\title{
ANÁLISE DA ASSISTÊNCIA AO BINÔMIO MÃE-BEBÊ EM CENTRO DE PARTO NORMAL
}

\author{
Flávia Ribeiro Rocha ${ }^{1}$, Manuela Costa Melo², Gerusa Amaral de Medeiros ${ }^{3}$, Érica Possidônea Pereira ${ }^{4}$, Lara \\ Mabelle Milfont Boeckmann ${ }^{5}$, Luz Marina Alfonso Dutra ${ }^{6}$
}

RESUMO: Objetivou-se compreender o atendimento ao binômio mãe-bebê em um Centro de Parto Normal da rede pública, com a especificidade do parto anterior na rede hospitalar. Trata-se de estudo descritivo com abordagem qualitativa, realizado com oito puérperas de Brasília, por meio de entrevista com roteiro semiestruturado. Os dados foram colhidos entre fevereiro e julho de 2015. Adotou-se a Análise do Conteúdo, Modalidade Temática, para o tratamento dos dados. Delinearam-se três categorias: "As Boas Práticas da Assistência e a Autonomia das Parturientes", "Cuidado versus Descaso" e "Insensibilidade com a Dor Alheia". Constatou-se que, no Centro de Parto Normal, houve o respeito às boas práticas na assistência ao parto e contentamento com $\mathrm{o}$ atendimento diferenciado. O estudo evidenciou o empoderamento das mulheres pela busca de informações sobre o processo de parir e seus direitos, e reforça a construção de mais Centros de Parto Normal, valorizando as boas práticas no processo de parturição.

DESCRITORES: Parto humanizado; Enfermeiras obstétricas; Avaliação de serviços de saúde; Período pós-parto; Relações profissional-família.

\section{ANALYSIS OF CARE TO THE MOTHER-BABY BINOMIAL IN A CENTER FOR NORMAL DELIVERY}

ABSTRACT: The present study aimed to gain insight on care to the mother-baby binomial in a Center for Normal Delivery of Brazil's public health network, for women who had previous deliveries in the hospital network. Descriptive qualitative study with eight women resident in Brasilia who had just given birth, through semi-structured interviews. Data was collected between February and July 2015. For data treatment, content analysis in thematic modality was used. Three categories emerged: "Good Delivery and Birth Care Practices and Parturients' Autonomy in the Decision-making Process", "Care versus Neglect" and "Indifference to the Suffering of Others". The Center for Normal Delivery implemented good delivery and birth care practices, and the participants were satisfied with the care provided to them. The study showed the women's empowerment to become more involved and informed on the process of giving birth and on their rights and stresses the need for the establishment of more Normal Birth Centers in the country to ensure good birth care practices.

DESCRIPTORS: Humanized delivery; Obstetric nurses; Assessment of health services; Postpartum period; Health professionalfamily relations.

\section{ANÁLISIS DE LA ASISTENCIA AL BINOMIO MADRE-BEBÉ EN CENTRO DE PARTO NATURAL}

RESUMEN: Estudio cuya finalidad fue comprender el atendimiento al binomio madre-bebé en un Centro de Parto Natural de la red pública, con especificidad del parto anterior en la red hospitalar. Es un estudio descriptivo de abordaje cualitativo, realizado con ocho puérperas de Brasília, por medio de entrevista con guion semiestructurado. Los datos fueron obtenidos entre febrero y julio de 2015. Se utilizó el Análisis de Contenido, Modalidad Temática, para el tratamiento de las informaciones. Resultaron tres categorías: "Buenas Prácticas de la Asistencia y Autonomía de las Parturientas", "Cuidado versus Descaso" y "Insensibilidad con el Dolor Ajeno". Se concluyó que, en el Centro de Parto Natural, hubo respeto a las buenas prácticas en la asistencia al parto y satisfacción con el atendimiento diferenciado. El estudio evidenció el empoderamiento de las mujeres por la búsqueda de informaciones acerca del proceso de parir y sus derechos, y destaca la importancia de la construcción de más Centros de Parto Natural, valorando las buenas prácticas en el proceso de parto.

DESCRIPTORES: Parto humanizado; Enfermeras obstétricas; Evaluación de servicios de salud; Periodo posparto; Relaciones profesional-familia.

${ }^{1}$ Enfermeira. Especialista em Enfermagem Obstétrica. Maternidade Brasília. Brasília, DF, Brasil.

${ }^{2}$ Enfermeira. Mestre em Ciências da Saúde. Docente da Escola Superior em Ciências da Saúde. Brasília, DF, Brasil.

${ }^{3}$ Enfermeira. Especialista em Enfermagem Obstétrica. Enfermeira obstetra do Centro Obstétrico do Hospital Regional da Asa Norte. Brasília, DF, Brasil.

${ }^{4}$ Enfermeira. Mestre em Enfermagem. Enfermeira obstetra do Centro Obstétrico do Hospital Regional da Asa Norte. Brasília, DF, Brasil.

${ }^{5}$ Enfermeira. Doutora em Enfermagem. Enfermeira Coordenadora do Núcleo de Segurança do Paciente do Hospital Regional de Taguatinga. Brasília, DF, Brasil.

${ }^{6}$ Enfermeira. Mestre em Ciências da Saúde. Preceptora do Programa de Residência da Secretaria Estadual de Saúde do Distrito Federal. Brasília, DF, Brasil. 


\title{
INTRODUÇÃO
}

O parto, até meados do século 20, era um acontecimento de natureza íntima e privativa, sendo compartilhado apenas entre mulheres, considerado fenômeno natural, cercado de significados culturais, e o nascimento celebrado como evento marcante da vida. Todavia, no decorrer dos anos, houve mudanças que tornaram essa cultura um acontecimento médico-hospitalar ${ }^{(1)}$.

Diante disso, o Brasil implantou políticas públicas aplicadas ao contexto da assistência obstétrica e neonatal visando à promoção do parto e do nascimento saudáveis e à prevenção da morbimortalidade materna e perinatal, de modo a garantir que profissionais médicos e enfermeirasparteiras realizem procedimentos comprovadamente benéficos para a mulher e neonato, evitando intervenções desnecessárias e preservando a privacidade e a autonomia desses sujeitos, reforçando assim as boas práticas de assistência ao parto ${ }^{(1)}$.

A Organização Mundial da Saúde (OMS), em 1996, categorizou as boas práticas prestadas ao parto de risco habitual em quatro níveis de evidência:

\begin{abstract}
Práticas que são demonstradamente úteis e que devem ser estimuladas; Práticas claramente prejudiciais ou ineficazes e que devem ser eliminadas; Práticas em relação às quais não existem evidências suficientes para apoiar uma recomendação clara e que devem ser utilizadas com cautela até que mais pesquisas esclareçam a questão; e Práticas frequentemente utilizadas de modo inadequado ${ }^{(2: 69-73)}$.
\end{abstract}

Com base nessas categorias, um estudo realizado em 13 hospitais de referência para parto de risco habitual, em Goiânia, identificou alta presença de práticas da categoria claramente prejudiciais ou ineficazes e que devem ser eliminadas, em contraste com as práticas que são úteis e que devem ser estimuladas - como baixo uso do partograma, alto índice de partos na posição supina e ausência de acompanhante $^{(3)}$.

Com o intuito de adequar cenário semelhante ao dessa pesquisa, o Ministério da Saúde publicou a Portaria 985/GM, de cinco de agosto de 1999, que ressalta a necessidade de humanização e da melhoria da assistência à gravidez, ao parto e ao puerpério e, consequentemente, da diminuição dos óbitos por

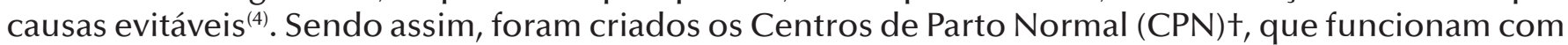
a presença e supervisão de enfermeiros obstetras e atendem gestantes de risco habitual e, quando necessária, é realizada a transferência para hospitais de referência.

O CPN é fortalecido pela Portaria 1.459, de 2011 do Ministério da Saúde, que instituiu a estratégia da Rede Cegonha, que, no componente Parto e Nascimento, incluiu as boas práticas de atenção ao parto e ao nascimento ${ }^{(5)}$. Essa estratégia, fundamentada nos princípios de humanização da assistência, fortalece a garantia do atendimento de qualidade às mulheres, desde a confirmação da gestação até os dois primeiros anos de vida do bebê.

Ademais, a Resolução 223, de 1999, do Conselho Federal de Enfermagem, atribui ao enfermeiro obstetra ou com certificado de obstetriz, bem como ao especialista em enfermagem obstétrica e na saúde da mulher, respaldo legal para realização do atendimento à parturiente e ao parto normal sem distócia e a emissão de laudo de enfermagem para Autorização de Internação Hospitalar, além de outras atribuiç̧̃̃es ${ }^{(6)}$.

Os enfermeiros obstetras comumente exercem essa ampla autonomia em CPN, e suas condutas são valorizadas pelas mulheres, que relatam satisfação com as explicações fornecidas, as orientações, a receptividade, o respeito, a paciência, o carinho e a presença do profissional durante todo o processo(7).

Assim, este estudo envolve a compreensão da assistência no CPN quanto ao cuidado e atendimento no contexto da enfermagem. As evidências produzidas neste estudo podem contribuir para as mulheres superarem as tensões que podem surgir neste período, e fortalecer as estratégias utilizadas pelos enfermeiros.

tO Ministério da Saúde (MS) enfatiza a implantação de maternidades simplificadas, formalmente denominada Centro de Parto Normal (CPN) ou Casa de Parto, porém, neste estudo iremos utilizar o termo CPN por ser o utilizado pelo MS, quando instituiu a estratégia da Rede Cegonha, em 2011. 
A partir das reflexões, o presente estudo objetivou compreender o atendimento ao biônimo mãebebê em uma casa de parto da rede pública, com a especificidade do parto anterior na rede hospitalar.

\section{MÉTODO}

A abordagem qualitativa constituiu o alicerce metodológico deste estudo descritivo. Foi escolhido como cenário o CPN localizado em Brasília, Distrito Federal. Atualmente ele é composto por 17 enfermeiros obstetras e 12 técnicos de enfermagem, que recebem gestantes de risco habitual conforme protocolo de atendimento, e possui o Hospital Regional do Paranoá como referência.

Para a definição da amostra intencional, foram elaborados os seguintes critérios de inclusão: puérperas acima de 18 anos internadas no CPN, lúcidas e orientadas, que tiveram experiência anterior com o parto normal de risco habitual na rede hospitalar, e experiência com o parto subsequente no CPN. Puérperas menores de 18 anos foram excluídas.

A coleta de dados foi realizada no período entre fevereiro e julho de 2015. Os contatos iniciais foram realizados por meio de visitas de campo, utilizando como instrumento um roteiro de entrevista semi-estruturado, elaborado com linguagem clara e acessível, composto pelas seguintes perguntas norteadoras: Por que a senhora escolheu o CPN? Que diferenças foram percebidas entre o CPN e o hospital que a senhora deu à luz anteriormente, em relação a esses itens: dieta oferecida desde que foi internada, respeito a suas decisões, métodos de alívio da dor, direito ao acompanhante, posição para o parto, corte vaginal (pique) e contato pele a pele com o bebê após o nascimento. A senhora ficou satisfeita com o atendimento no hospital durante o trabalho de parto e parto? Por quê? A senhora está satisfeita com o atendimento no CPN durante o trabalho de parto e parto? Por quê?

Cada entrevista foi realizada pela pesquisadora principal em local reservado para tal finalidade, com a presença apenas da entrevistada e da pesquisadora. Para definição do número de participantes na pesquisa, foi utilizada a ferramenta conceitual denominada saturação teórica, que permite cessar o número de participantes a partir do momento em que os objetivos são alcançados e que os resultados passam a se repetir e a não contribuir ou pouco acrescentar para o aperfeiçoamento da análise ${ }^{(8)}$.

As entrevistas foram realizadas com um gravador digital e tiveram duração média de 20 minutos. Logo após, foram ouvidas e transcritas de maneira integral. Para a garantia do anonimato das puérperas, foi utilizada a letra $\mathrm{P}$ para a identificação das falas seguida da sequência cronológica das entrevistas realizadas. Após cada entrevista, foi utilizado o diário de campo, no qual foram anotados os dados significativos da pesquisadora envolvida na execução do estudo.

Após a realização da pesquisa de campo, cada entrevista foi relida e foram iniciadas as etapas de análise. Utilizou-se a Análise de Conteúdo Temática ${ }^{(9)}$ para o tratamento dos depoimentos, que foram examinados por duas pesquisadoras (a pesquisadora principal e uma juíza independente). A interpretação das informações coletadas ocorreu à luz da produção científica nacional e internacional, e da legislação brasileira que enfoca o assunto.

A presente pesquisa atendeu às determinações estipuladas pelas normas do Conselho Nacional de Saúde - Diretriz e Normas Regulamentadoras Envolvendo Seres Humanos - Resolução CNS $\mathrm{n}^{\mathrm{o}}$ 466/2012(10). A pesquisa foi aprovada pelo Comitê de Ética em Pesquisa da Fundação de Ensino e Pesquisa em Ciências da Saúde (CEP/FEPECS), sob o Parecer nº 979.367, de 9 de março de 2015 e CAEE $\mathrm{n}^{\mathrm{o}}$ 40397214.0.0000.5553.

\section{- RESULTADOS}

Foram entrevistadas oito puérperas. Inicialmente, identificou-se a caracterização sociodemográfica: três intitularam-se brancas, duas pardas e três não souberam responder. A idade das entrevistadas ficou entre 30 e 40 anos. Com relação à escolaridade: uma mulher era analfabeta, duas frequentaram o Ensino Fundamental, três cursaram o Ensino Médio, e duas concluíram o Ensino Superior.

No quesito local de residência: seis entrevistadas residiam na região Leste do Distrito Federal, 
região próxima ao CPN, uma em Águas Claras (Distrito Federal) e outra em Goiás. No questionamento a respeito da inserção no mercado de trabalho, cinco exerciam atividade remunerada. Detectou-se que seis mulheres tinham algum tipo de relacionamento com o pai da criança, e duas declararamse solteiras. Quanto à história reprodutiva, seis eram secundíparas e duas, multíparas. Cinco delas tiveram seu último parto entre 2006 e 2013, duas entre 2000 e 2005, e uma teve o último parto anterior ao ano 2000.

$\mathrm{Na}$ realização do procedimento analítico, buscou-se compreender a percepção das puérperas durante a assistência no CPN. Esses aspectos subsidiaram três categorias temáticas: "As Boas Práticas da Assistência e a Autonomia das Parturientes", "Cuidado versus Descaso" e "Insensibilidade com a Dor Alheia".

\section{As Boas Práticas da Assistência e a Autonomia das Parturientes}

Nessa categoria, foram abordados os seguintes temas: respeito às decisões das mulheres, autonomia na escolha da posição para o parto, realização de episiotomia, dieta oferecida durante o trabalho de parto, contato pele a pele com o recém-nascido após o nascimento, e direito ao acompanhante durante toda a internação.

Referente ao parto anterior, a despeito de grande parte das puérperas tenha relatado que suas decisões foram respeitadas durante a assistência hospitalar, suas falas revelaram que não foram informadas ou questionadas sobre a realização da episiotomia e nem puderam optar em relação à melhor posição para o parto. A puérpera relatou o seguinte:

Lá eles fizeram corte, não perguntaram se eu queria, foi em última hora, o menino não queria sair [...]. $(P 2)$

Uma das participantes justificou a falta de autonomia nas decisões pelo fato de ser muito nova na primeira gestação e ter pouco conhecimento a respeito do parto humanizado, das boas práticas na assistência e de seus direitos enquanto usuária:

Ah, eu era muito criança né! Eu tinha 17 anos, eu não sabia que essa episiotomia, essa ocitocina que aplicavam na gente, era toque demais, para mim era tudo normal, mas depois que fui ver tava errado. (P5)

Em contrapartida, no parto atual, no CPN, todas as mulheres tiveram suas decisões respeitadas, não receberam episiotomia e puderam escolher a posição para o parto, exceto duas participantes que chegaram em período expulsivo e relatam que foi muito rápido, por isso não deu tempo. Afirmou:

[...] aqui eu pude escolher [posição]. (P2)

Aqui eles cuidaram, rasgou um pouquinho mais eles cuidaram mais do que lá. (P6)

A prática hospitalar de internar as parturientes com prescrição de dieta zero demonstrou ser comum, enquanto que, no CPN, as mulheres tiveram suas dietas liberadas durante todo o processo de parturição:

No hospital não permitiram que eu me alimentasse nem que eu bebesse água. Aqui desde o momento que cheguei foi me oferecido tudo, chá, biscoito, água, então o que eu pude comer e o que eu quis comer e beber eles permitiram. (P8)

Lá [hospital] recebi só depois que ganhei, não deixou nem beber água. Aqui foi liberado, já comi, já bebi desde o início. (P7)

O contato pele a pele com o recém-nascido após o nascimento, importante conduta para a formação de vínculo entre mãe e bebê, foi pouco respeitado no hospital. As mulheres disseram que tiveram pouco tempo para ficarem com seu filho após o nascimento. No CPN essa prática foi estimulada e respeitada. As puérperas mencionaram:

Muito pouco, botaram e tiraram [hospital], aqui eu tive até demais, ela nasceu 6 e pouco tiraram de mim 
já ia dar 10 horas. (P2)

Não, ficou não, tiraram ficaram longe de mim, [hospital] aqui teve, eles colocaram em cima de mim, assim que nasceu eles já deram fiquei mais de uma hora. (P6)

Questionadas em relação à presença do acompanhante, as mulheres disseram que alguns hospitais não aceitaram a presença de alguém junto a elas, mesmo com Lei do Acompanhante, em vigor desde 2005. Dessas puérperas, apenas uma teve parto anterior a essa lei. Em contrapartida, no CPN todas puderam ficar com seus acompanhantes e, opcionalmente, em alguns casos, uma doula - situação apresentada conforme os seguintes relatos:

Lá não podia [hospital], aqui teve ele [marido] e a doula. (P5)

No hospital não, porque responderam mal botaram para casa né, eles não aceitaram, mas aqui eles aceitaram. (P6)

\section{Cuidado versus Descaso}

Essa categoria se referiu às seguintes temáticas: resultados relacionados às satisfações e insatisfações do atendimento no hospital e no CPN, e motivo da escolha desse local. As mulheres mostraram-se insatisfeitas com a forma com que foram tratadas nos hospitais. Relataram abandono, grosserias e falta de orientações:

[...] lá me largaram num quarto, depois foram me buscar me levaram para um outro, aí quando eu tava indo para o que eu ia ficar né, caí lá e elas me largaram lá caída em cima da cama [...] eu desmaiei lá. (P1)

[...] alguns médicos eram muito grossos [...]. (P4)

A satisfação com o atendimento no CPN foi unânime. Entre as falas, os aspectos que mais se destacaram foram o carinho, o respeito e o cuidado da equipe com as mulheres. Algumas puérperas, com indagação sobre o atendimento no CPN, afirmaram:

Ah, eu gostei porque todo mundo tem paciência com a gente, fica Ihe ajudando, não fica estressado, entendeu? Então isso Ihe dá mais, sei lá, mais confiança e eu gostei muito, não tenho que falar não. (P2)

[...] eu fui respeitada, eu fiz o que foi melhor para mim e para o meu bebê e isso para mim fez toda diferença. (P8)

As puérperas escolheram o CPN principalmente por ser perto de suas residências e por terem considerado o atendimento melhor que no hospital. Relataram ainda sobre o local oferecer assistência humanizada:

Eu queria algo diferente, porque na primeira gestação eu sofri um pouco com aquela episiotomia. Ai eu comecei a curti coisas de parto no Facebook e vi que tinha essa coisa de parto humanizado que até então eu não sabia, aí eu fui buscando mais conhecimento e tal e falei eu quero esse parto para mim. (P5)

\section{Insensibilidade com a Dor Alheia}

Essa categoria abrangeu a temática a respeito da utilização dos métodos não farmacológicos para alívio da dor no hospital e no CPN. As entrevistadas revelaram que não utilizaram método não farmacológico para alívio da dor em seus partos anteriores no hospital, enquanto que, no CPN, a maioria relatou que foi orientada e estimulada a utilizar algum método não farmacológico. Somente aquelas que chegaram em período expulsivo de trabalho de parto relataram não o terem utilizado:

Deixaram à vontade [Casa de Parto], tiveram tudo, isso lá eu não tive isso. (P3)

No hospital não teve, aqui eu utilizei de tudo, muito bom. (P7) 


\section{- DISCUSSÃO}

No decorrer do desenvolvimento deste estudo, foram compreendidos alguns aspectos relacionados às boas práticas na assistência ao parto, e ficaram claras as divergências entre as experiências vivenciadas no hospital e no CPN. Tais resultados corroboraram com resultados de estudo semelhante realizado em Londres ${ }^{(11)}$, o qual comparou, dentre outros pontos, o respeito à escolha da posição para parir e a realização da episiotomia. No CPN foi constatado o respeito à escolha da posição para parir, sendo que, no hospital, a posição apresentada foi a supina. E em relação à episiotomia, conforme este mesmo estudo, o procedimento só foi realizado em mulheres no parto hospitalar.

Outra prática identificada no parto hospitalar é que as parturientes não foram questionadas ou informadas sobre os procedimentos realizados em seu corpo, e não souberam explicar o real motivo de determinadas condutas. O corpo dessas mulheres acaba sendo tratado como instrumento de ensino e aprendizagem prática, sem que fossem considerados os aspectos humanos ou psicológicos causados por tais intervenções. O estudo apresentou que algumas parturientes até são informadas a respeito dos procedimentos, mas não têm condições de decidir, sendo essa decisão exclusiva do médico, consolidando a ideia da superioridade médica frente ao processo parturitivo - que não pertence a ele ${ }^{(12)}$.

Com relação à liberdade de posição, à ingestão de alimentos e à utilização de métodos não farmacológicos de alívio da dor, boas práticas relevantes na assistência ao parto, também coincidiram com os resultados encontrados em estudo anterior realizado no mesmo CPN, o que reforça que este serviço funciona como aliado na diminuição das intervenções - muitas vezes desnecessárias realizadas na assistência ao parto no Brasil ${ }^{(13)}$.

Outra boa prática utilizada na valorização do nascimento é o contato pele a pele da mãe com o recém-nascido. A Iniciativa Hospital Amigo da Criança (IHAC) recomenda que esse contato seja de no mínimo uma hora para os bebês que nascem com boa vitalidade ${ }^{(14)}$ e este contato imediato facilita o início da amamentação(11). Esta prática é incentivada e aplicada nos CPN.

Este estudo também reforçou que a restrição de alimentos durante o trabalho de parto, no hospital, é uma prática comum. A pesquisa Nascer no Brasil, realizada nas maternidades brasileiras, demonstrou que menos de um terço das parturientes de risco habitual alimentou-se durante o trabalho de parto ${ }^{(15)}$. Exemplo disso, em Goiânia-GO, em 13 dos 14 hospitais de referência para o parto de risco habitual, $62 \%$ das mulheres permaneceram em dieta zero ${ }^{(3)}$. No CPN, não há restrições, e as mulheres relataram que essa prática é benéfica para dar força no período expulsivo ${ }^{(16)}$.

No processo parturitivo, a presença de um acompanhante faz-se importante como boa prática para o trabalho de parto e parto. A Lei $n^{\circ} 11.108 / 2005$ prevê o direito ao acompanhante de livre escolha durante todo o período de trabalho de parto, parto e pós-parto ${ }^{(17)}$. Mulheres que tiveram seus filhos em CPN expressaram que a presença do acompanhante lhes proporcionou segurança, tranquilidade, amparo e liberdade para demonstrarem o que estavam sentido, além de ter sido um apoio significativo para a realização de suas atividades ${ }^{(18)}$. No contexto da assistência nos CPN, isto tem sido uma premissa importante. A presença do acompanhante em um CPN do Rio de Janeiro, por exemplo, contemplou $94,9 \%$ dos partos atendidos ${ }^{(19)}$.

A assistência prestada e a forma de relacionamento entre parturiente e profissional de saúde também são detalhes importantes frente à humanização do parto e nascimento. Em um CPN, o acompanhamento constante pelos profissionais gerou nas mulheres maior satisfação, menos solidão e maior segurança ${ }^{(18)}$. O respeito, a paciência e o carinho também foram aspectos valorizados nos resultados deste estudo.

Diante de tal cenário, cada vez mais mulheres procuram os $\mathrm{CPN}$, seja por morarem próximos à instituição, conforme constatado neste estudo, ou por experiências positivas de outras mulheres, no intuito de ter um tipo de assistência diferenciada e humanizada. Em estudo realizado em dois hospitais em Maringá-PR, com 569 mulheres, que caracterizou o atendimento hospitalar ao parto, foi constatada a necessidade de buscar assistência diferenciada, haja vista que essas instituições apresentaram diversas dificuldades, seja com relação à estrutura física, rotinas hospitalares ou ainda a posturas individuais 
dos profissionais de saúde. Tais dificuldades representam obstáculos para o modelo humanizado ao parto e ao nascimento(20).

Os CPN também se destacam com a utilização de métodos não farmacológicos de alívio da dor. O profissional de saúde tem importante papel de informar e orientar a mulher a como lidar com a própria dor, através de exercícios respiratórios, banho de chuveiro, deambulação, exercícios na bola e de agachamento, realização de massagens ou qualquer outro recurso que ajude a mulher nesse processo $^{(21)}$. De acordo com as parturientes, os métodos não farmacológicos de alívio da dor são positivos, apesar de não solucionarem o problema, ajudam a desviar o foco da sensação desagradável. Em hospitais nos quais esses procedimentos são ofertados, a equipe de enfermagem é a principal incentivadora ${ }^{(20)}$.

Embora este estudo tenha apresentado algumas limitações, como o fato de as mulheres entrevistadas terem pouco ou nenhum conhecimento das práticas humanizadas de assistência, ficou claro, a partir de seus depoimentos, que as boas práticas referidas nesse estudo foram cumpridas no CPN. Outra limitação foi o distanciamento entre o parto hospitalar com o realizado no CPN, pois o parto hospitalar ocorreu há certo tempo, no qual preconizava o modelo biomédico, evidenciando os relatos negativos. sabido que esse modelo, na rede hospitalar, encontra-se em processo de mudança, e muitos hospitaismaternidades procuram estruturar e aplicar as boas práticas na assistência ao trabalho de parto e parto.

\section{- CONSIDERAÇÕES FINAIS}

Este estudo correspondeu ao objetivo proposto, ao evidenciar que as participantes apontaram que a assistência prestada no CPN está de acordo com as boas práticas recomendadas pela OMS enquanto que, nos hospitais, muito ainda precisa ser adequado na busca de assistência humanizada. No ambiente hospitalar, as experiências expressadas pelas mulheres revelaram condutas obsoletas, além de desrespeito e falta de empatia no atendimento.

Contrastando com essa realidade, o CPN do Distrito Federal demonstrou ser um ambiente acolhedor e com profissionais capacitados para a realização de atendimento humanizado e voltado para as recomendações da OMS. As mulheres tiveram seus direitos respeitados e sua autonomia incentivada, além do devido cuidado para que passassem por esse processo da forma mais suave e prazerosa.

Considerando os resultados desta pesquisa, destacamos a necessidade de construção de mais unidades de CPN, nos quais a mulher seja respeitada em todo o processo de parturição e o enfermeiro obstetra valorizado, considerando a importância desse profissional para promoção das boas práticas na assistência ao parto.

\section{REFERÊNCIAS}

1. Ministério da Saúde (BR). Secretaria de Políticas de Saúde. Área Técnica de Saúde da Mulher. Parto, aborto e puerpério. [Internet] Brasília: Assistência humanizada à mulher; 2001 [acesso em 3 fev 2016]. Disponível: http:// pfdc.pgr.mpf.mp.br/temas-de-atuacao/mulher/saude-das-mulheres/enfrentamento-a-mortalidade-maternamenu/parto-aborto-e-puerperio-assistencia-humanizada-a-mulher-ms.

2. Organização Mundial da Saúde (OMS). Assistência ao Parto Normal: um guia prático. (Relatório Técnico). Genebra; 1996.

3. Giglio MRP, França E, Lamounier JA. Avaliação da qualidade da assistência ao parto normal. Rev. Bras. Ginecol. Obstet. [Internet] 2011;33(10) [acesso em 3 fev 2016]. Disponível: http://dx.doi.org/10.1590/S010072032011001000005 .

4. Ministério da Saúde (BR). Portaria MS/GM n. 985, de 5 de agosto de 1999. Implementa e regulamenta o funcionamento dos Centros de Parto Normal em âmbito do Sistema Único de Saúde. Diário Oficial da União, Brasília, 5 ago. 1999.

5. Ministério da Saúde (BR). Portaria n. 1.459, de 24 de junho de 2011. Institui no âmbito do Sistema Único de 
Saúde - SUS - a Rede Cegonha. Diário Oficial da União, Brasília, 24 jun. 2011.

6. Conselho Federal de Enfermagem. Resolução n. 223, de 3 de dezembro de 1999. Dispõe sobre a atuação de Enfermeiros na Assistência à Mulher no Ciclo Gravídico Puerperal. Rio de Janeiro: COFEN; 1999.

7. Malheiros PA, Alves VH, Rangel TSA, Vargens OMC. Labor and birth: knowledge and humanized practices. Texto Contexto Enferm. [Internet] 2012;21(2) [acesso em 9 fev 2016]. Disponível: http://dx.doi.org/10.1590/S010407072012000200010 .

8. Fontanella BJB, Ricas J, Turato ER. Amostragem por saturação em pesquisas qualitativas em saúde: contribuições teóricas. Cad. Saúde Pública. [Internet] 2008;24(1) [acesso em 3 fev 2016]. Disponível: http://dx.doi.org/10.1590/ S0102-311X2008000100003.

9. Bardin L. Análise de Conteúdo. Lisboa: Edições 70; 2009.

10. Ministério da Saúde (BR). Conselho Nacional de Saúde. Diretrizes e normas regulamentadoras de pesquisa envolvendo seres humanos. Resolução n. 466 de 12 de dezembro de 2012. Brasília; 2012.

11. Macfarlane AJ, Rocca-Ihenacho L, Turner LR. Survey of women's experiences of care in a new freestanding midwifery unit in an inner city area of London, England: 2. Specific aspects of care. Midwifery. [Internet] 2014;30(9) [acesso em 9 jan 2016]. Disponível: http://dx.doi.org/10.1016/j.midw.2014.05.008.

12. de Carvalho VF, Kerber NPC, Busanello J, Gonçalves BG, Rodrigues EF, de Azambuja EP. Como os trabalhadores de um Centro Obstétrico justificam a utilização de práticas prejudiciais ao parto normal. Rev. esc. enferm. USP. [Internet] 2012;46(1) [acesso em 3 fev 2016]. Disponível: http://dx.doi.org/10.1590/S0080-62342012000100004.

13. Barros WLL, Costa E, Boeckmann LMM, dos Reis PED, de Leon CGRMP, Funghetto SS. Parto humanizado: uma realidade na Casa de Parto?. Rev enferm UFPE on line. [Internet] 2011;5(1) [acesso em 24 out 2015]. Disponível: http://www.revista.ufpe.br/revistaenfermagem/index.php/revista/article/viewFile/1207/pdf_277.

14. Ministério da Saúde (BR). Portaria n. 1.153, de 22 de maio de 2014. Redefine os critérios de habilitação da Iniciativa Hospital Amigo da Criança (IHAC), como estratégia de promoção, proteção e apoio ao aleitamento materno e à saúde integral da criança e da mulher, no âmbito do Sistema Único de Saúde (SUS). Diário Oficial da União, Brasília, 22 mai. 2014.

15. Leal MC, Pereira APE, Domingues RMSM, Theme Filha MM, Dias MAB, Nakamura-Peireira M, et al. Intervenções obstétricas durante o trabalho de parto e parto em mulheres brasileiras de risco habitual. Cad. Saúde Pública. [Internet] 2014;30(Suppl 1) [acesso em 3 fev 2016]. Disponível: http://dx.doi.org/10.1590/0102-311X00151513.

16. Wei CY, Gualda DMR, Santos Junior HPO. Movimentação e dieta durante o trabalho de parto: a percepção de um grupo de puérperas. Texto Contexto Enferm. [Internet] 2011;20(4) [acesso em 3 fev 2016]. Disponível: http:// dx.doi.org/10.1590/S0104-07072011000400010.

17. Ministério da Saúde (BR). Lei n. 11.108, de 7 de abril de 2005. Altera a Lei n. 8.080, de 19 de setembro de 1990, para garantir às parturientes o direito à presença de acompanhante durante o trabalho de parto, parto e pósparto imediato, no âmbito do Sistema Único de Saúde - SUS. Diário Oficial da União, Brasília, 8 abril. 2005.

18. Jamas MT, Hoga LAK, Reberte LM. Narrativas de mulheres sobre a assistência recebida em um Centro de Parto Normal. Cad. Saúde Pública. [Internet] 2013;29(12) [acesso em 3 fev 2016]. Disponível: http://dx.doi. org/10.1590/0102-311X00039713.

19. Pereira ALF, de Azevedo LGF, Medina ET, de Lima TRL, Schroeter MS. Maternal and neonatal care in David Capistrano Filho birth center, Rio de Janeiro, Brazil. R. pesq.: cuid. fundam. online. [Internet] 2012;4(2) [acesso em 3 fev 2016]. Disponível: http://dx.doi.org/10.9789/2175-5361.2012.v4i2.2905-2913.

20. Nagahama EEI, Santiago SM. Práticas de atenção ao parto e os desafios para humanização do cuidado em dois hospitais vinculados ao Sistema Único de Saúde em município da Região Sul do Brasil. Cad. Saúde Pública. [Internet] 2008;24(8) [acesso em 3 fez 2016]. Disponível: http://dx.doi.org/10.1590/S0102-311X2008000800014.

21. Pinheiro BD, Bittar CML. Percepções, expectativas e conhecimentos sobre o parto normal: relatos de experiência de parturientes e dos profissionais de saúde. Aletheia. [Internet] 2012;(37) [acesso em 3 fev 2016]. Disponível: http://pepsic.bvsalud.org/scielo.php?script=sci_arttext\&pid=S1413-03942012000100015\&lng=pt. 